\title{
Acremonium implicatum, a Seed-Transmitted Endophytic Fungus in Brachiaria Grasses
}

\author{
Huang Dongyi and Segenet Kelemu, Centro Internacional de Agricultura Tropical (CIAT), A.A. 6713, Cali, Colombia
}

\begin{abstract}
Dongyi, H., and Kelemu, S. 2004. Acremonium implicatum, a seed-transmitted endophytic fungus in Brachiaria grasses. Plant Dis. 88:1252-1254.

The pan-tropical grass genus Brachiaria comprises about 100 species, several of which are forages of economic importance, particularly in tropical America. Acremonium implicatum is a fungus that forms an endophytic association with at least some of these economically important grasses. To ascertain whether A. implicatum can be seed transmitted in Brachiaria species, we vegetatively propagated, under greenhouse conditions, 20 tillers from an endophyte-infected mother plant obtained from each of 14 Brachiaria hybrids and species. Ten tillers of each genotype were treated with the fungicide tebuconazole to eliminate the endophyte, and the other 10 were left untreated. Seeds were then harvested individually from all 20 of these genetically identical plants, germinated, and the seedlings grown. A previously developed polymerase chain reaction-based method used a pair of endophyte-specific primers to amplify a diagnostic 500-bp DNA fragment. The seedlings generated from seeds harvested from endophyte-infected plants also tested positive, whereas those from seeds of endophyte-free plants showed no amplification products. This is the first report of A. implicatum being transmitted through seeds of Brachiaria grasses.
\end{abstract}

Additional keywords: apomictic reproduction, endophyte-free Brachiaria, endophyte-plant association

Brachiaria is a pan-tropical genus of grasses with about 100 species, several of which have become commercially important forage grasses, particularly in tropical America.

The fungus Acremonium implicatum (Gilman \& E. Abbott) W. Gams can develop an endophytic association with Brachiaria species that is asymptomatic $(13,14)$. Endophyte-plant associations are widespread in nature (19). Grasses harboring nonpathogenic and intercellular endophytes benefit in various ways such as having enhanced drought tolerance and vigor $(4,22,23)$, and increased resistance to attacks from insect pests $(3,21,23)$ and pathogens $(7,9,14,15)$. Systemic infections of grasses in the Festuca and Lolium genera with Neotyphodium species and the

Corresponding author: S. Kelemu

E-mail: s.kelemu@cgiar.org

Our study was made possible through financial support received from the Government of Japan.

Present address of H. Dongyi: College of Agriculture, Chinese Academy for Tropical Agricultural Science (CATAS) and South China University of Tropical Agriculture (SCUTA), Danzhou City, Hainan Province, the People's Republic of China, 571737.

Accepted for publication 25 June 2004.

Publication no. D-2004-0902-03R

C 2004 The American Phytopathological Society corresponding teleomorph Epichlöe species have been studied extensively. These fungi are often transmitted by seed to the next host generation (23).

Many Brachiaria species are apomictic and reproduce asexually through seed (17). Apomictic reproduction permits plant genotypes to breed true through seed. This type of reproduction also offers advantages to research on endophyte-host associations and use. If the specific endophyte in question were seed-transmitted, almost all seeds of an endophyte-infected apomictic plant would contain the endophyte, as well as being genetically identical to each other.

Effective and reliable detection methods are key to studies on plant-microbe interactions. Polymerase chain reaction (PCR)based detection methods have been successfully applied in host-pathogen interactions (10), in endophyte-plant symbiotic associations $(5,6,8,12)$, and in pathogen seed-transmission studies (20).

We developed a PCR-based method for rapid and reliable detection of A. implicatum in tissues of Brachiaria grasses. We first amplified DNA from isolates of $A$. implicatum, using 10-base random primers. Primer OPAK 10 (Operon Technologies, Inc., now QIAGEN Operon, Valencia, CA) amplified various bands, including a 500-bp product that was common to all the isolates tested. This fragment was cloned and sequenced (12), and the sequence data were used to design and synthesize several primers. The following primer pair was finally selected: P1 (5'-TTCGAATGATAAGGCAGATC-3') and P4 (5'-ACGCATCCACTGTATGCTAC- $3^{\prime}$ ).

The primer pair amplified the 500-bp product with template DNA from isolates of A. implicatum in pure cultures and in tissues of Brachiaria grasses infected with A. implicatum. No amplification product was detected in the controls, which comprised plants free of A. implicatum, or in the DNA of nonendophytic fungi or bacteria (e.g., Xanthomonas campestris pv. graminis) associated with Brachiaria species (12).

This primer pair was then used to conduct seed-transmission studies in plants containing A. implicatum. We report our findings below. Parts of this work have already been published as a preliminary report by Kelemu and Dongyi (11).

\section{MATERIALS AND METHODS}

Brachiaria genotypes used. Nine Brachiaria hybrids (SX99/1616, SX99/ 3488, SX99/0275, SX99/1513, SX99/ 0731, BR99NO/4015, BR99NO/4132, FM9201/1873, and FM9503/S046/024), four accessions (B. decumbens CIAT 606, B. brizantha CIAT 26110, CIAT 16320, and CIAT 6780), and one tetraploid parental line (BRUZ4X/4402) were obtained from the tropical forages breeding program of Centro Internacional de Agricultura Tropical (Palmira, Colombia). FM9201/ 1873 was later named CIAT 36061 or cultivar Mulato, the first commercial Brachiaria hybrid. A number of these genotypes were naturally infected with A. implicatum. A tracking number (see captions of Figures 1 to 3 , numbers in parentheses right after Brachiaria genotype codes or accession numbers) was added to each plant to show the transmission of A. implicatum from specific plants.

Brachiaria hybrids BR99NO/4015, BR99NO/4132, FM9201/1873 (cv. Mulato), and FM9503/S046/024, and B. decumbens CIAT 606, B. brizantha CIAT 26110, CIAT 16320, and CIAT 6780 are apomictic. Hybrids SX99/1616, SX99/ 3488, SX99/0275, SX99/1513, and SX99/ 0731, and the parental line BRUZ4X/4402 are sexual.

Plant inoculations. To inoculate some Brachiaria genotypes with isolates of $A$. implicatum, we used a modified version of the seedling shoot apical meristem inoculation method described by Latch and Christensen (16). Seeds were surfacesterilized with $70 \%$ ethanol for $2 \mathrm{~min}$, 
$2.5 \%$ sodium hypochlorite for $10 \mathrm{~min}$, and then washed three times with sterile distilled water. Ten seeds were placed in each Magenta vessel (Sigma-Aldrich, St. Louis, MO) containing basal MS medium (18) and left to germinate at room temperature. Three-week-old seedlings were inoculated with mycelia from an actively growing culture of the endophyte. A small amount of mycelia was introduced into the apical meristem of each seedling, using a delicate entomological needle and with the aid of a binocular stereomicroscope in a laminar flow hood. The inoculation point was carefully sealed with sterile Vaseline to prevent fungal contamination of, and growth on, the medium. The inoculated plants were replanted into fresh MS medium and left to grow for about another 9 days. The plants were then removed from the medium and transplanted to beakers containing nutrient solution and left for $24 \mathrm{~h}$ before being transplanted to pots containing sterilized soil.

Four to six weeks after inoculation, the presence or absence of the endophyte in the artificially inoculated plants was determined by culturing or staining leaf sheaths, as described by Kelemu et al. (14), and/or by PCR analysis (12). These plants were also grown to maturity and produced seed for further seedtransmission tests in the seeds and seedlings generated.

Endophyte elimination. The fungicide tebuconazole (brand name: Folicur; chemical name: (RS)-1-p-chlorophenyl-4,4dimethyl-3-(1H-1,2,4-triazol-1-ylmethyl) pentan-3-ol) was used to generate endophyte-free Brachiaria clones as described in Kelemu et al. (14). Twenty or more plantlets were propagated from a mother plant of a particular Brachiaria genotype already naturally or artificially infected with A. implicatum. Half of these plantlets were soaked in a solution of $0.6 \mathrm{ml} / \mathrm{liter}$ of tebuconazole at $250 \mathrm{~g}$ a.i./liter for $6 \mathrm{~h}$ to eliminate the endophyte. The other 10 were left untreated to serve as a control. All of the tillers were individually planted in small pots and placed in the greenhouse. Plants were examined 4 to 6 weeks after treatment for the presence or absence of $A$. implicatum.

At 6 weeks old, half of the seedlings were transplanted to big pots in the greenhouse and the other half to the field at CIAT for seed production for a period of 6 to 12 months. Seeds were then harvested from both potted and field plants. After recording the origin of each seed lot, seed samples from each plant were tested for the presence or absence of A. implicatum. Samples were also surface-sterilized in $70 \%$ ethanol for $2 \mathrm{~min}, 2.5 \%$ sodium hypochlorite for $10 \mathrm{~min}$, and then washed three times with sterile distilled water. Excess moisture was removed by blotting on sterile paper towels.

The disinfected seeds were placed in Magenta vessels (Sigma-Aldrich) contain- ing basal MS medium (18) and left to germinate at room temperature. When the seedlings were 4 to 5 weeks old, they were transplanted into sterilized soil in pots and grown in the greenhouse at temperatures between 19 and $30^{\circ} \mathrm{C}$. Tissues from these plants were tested for the presence of $A$. implicatum.

Fungal cultures. Isolates of A. implicatum were grown on sterile filter papers laid over potato dextrose agar (PDA) and incubated at $28^{\circ} \mathrm{C}$. Once the fungus fully covered them, the filter papers were removed from the agar and air-dried. These were placed in sterile envelopes and stored in plastic boxes at $-20^{\circ} \mathrm{C}$. For DNA extractions, plant inoculations, or other studies, the fungal isolates were revived by plating pieces of filter paper carrying mycelia on fresh PDA.

DNA isolations. We collected (i) fresh mycelia of endophyte isolates cultured on PDA plates, (ii) tissues and seeds from naturally endophyte-infected plants, (iii) tissues and seeds from endophyte-free plants, and (iv) tissues and seeds from artificially inoculated plants. Each tissue type was macerated separately in liquid nitrogen for genomic DNA isolation, which was carried out with DNeasy Plant

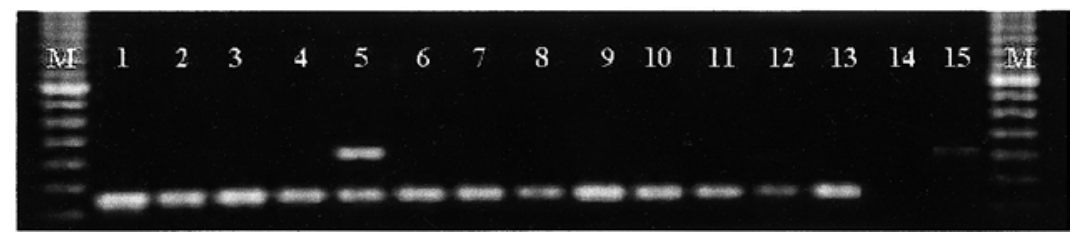

Fig. 1. Specific detection of the endophytic fungus Acremonium implicatum in tissues of Brachiaria plants using polymerase chain reaction (PCR) with primer pair P1/P4. Lanes 1 to 12 , template DNA of Acremonium-infected Brachiaria hybrid plants SX99/1616 (7), SX99/3488 (8), SX99/0275 (14), BR99NO/4132 (22), SX99/1513 (23), FM9201/1873 (29), BR99NO/4015 (37), BR99NO/4132 (39), CIAT 606 (42), BRUZ4X/4402 (44), FM9201/1873 (48), and SX99/0731 (52), respectively; lane 13, B. brizantha CIAT 26110 (15) artificially inoculated with A. implicatum isolate EB6780 (201); lanes 14 and 15, endophyte-free B. brizantha CIAT 16320 (32-25) and B. brizantha CIAT 16320 (32-29), respectively: plants derived from naturally endophyte-infected tillers whose endophytes were successfully eliminated by treatment with the fungicide tebuconazole $(0.6 \mathrm{ml} / \mathrm{liter})$ for $6 \mathrm{~h}$; lane $\mathrm{M}, 100$ bp ladders. Numbers in parentheses after Brachiaria genotype codes or accession numbers are individual plant-tracking numbers.

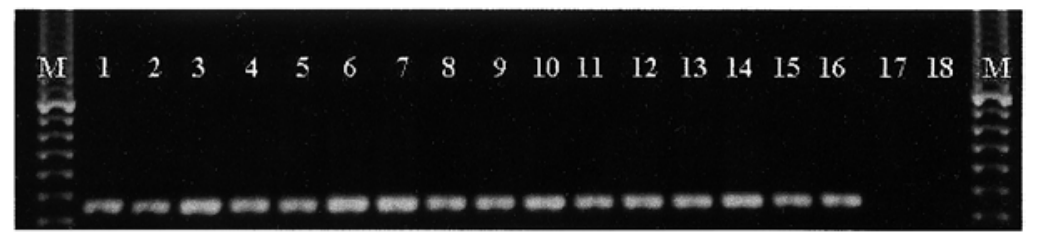

Fig. 2. Specific detection of the endophytic fungus Acremonium implicatum in seeds harvested from endophyte-infected Brachiaria plants using polymerase chain reaction (PCR) with primer pair P1/P4 Lanes 1 to 16, amplifications of template DNA extracted from seeds of endophyte-infected Brachiaria grasses SX99/3488 (8), SX99/0275 (14), BR99NO/4132 (22), FM9201/1873 (29), BR99NO/4015 (37), BR99NO/4132 (39), B. decumbens CIAT 606 (42), BRUZ4X/4402 (44), FM9201/1873 (48), SX99/0731 (52), B. brizantha CIAT 16320 (32), FM9503/S046/024 (45), B. brizantha CIAT 26110 (15), B. brizantha CIAT 6780 (56), B. brizantha CIAT 6780 (68), and B. brizantha CIAT 6780 (111), respectively; lanes 17 and 18, DNA extracted from seeds of endophyte-free plants of $B$. brizantha CIAT 16320 (32-25) and B. brizantha CIAT 16320 (32-29): genetically identical plants vegetatively propagated from CIAT 16320 (32); lane M, 100-bp ladders. B. brizantha CIAT 26110 (15), B. brizantha CIAT 6780 (56), B. brizantha CIAT 6780 (68), and B. brizantha CIAT 6780 (111) were artificially infected. All others were naturally infected. Numbers in parentheses after Brachiaria genotype codes or accession numbers are individual plant-tracking numbers.

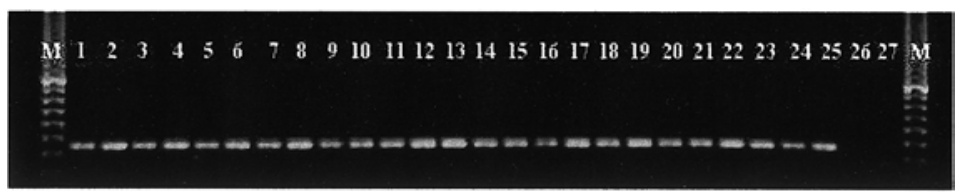

Fig. 3. Specific detection of the endophytic fungus Acremonium implicatum in seedlings generated from seeds of endophyte-infected and endophyte-free Brachiaria plants using polymerase chain reaction (PCR) with primer pair P1/P4. Lanes 1 to 7 , seedlings from seeds harvested from naturally endophyte-infected plants SX99/3488 (8), BRN99NO/4132 (22), BRN99NO/4132 (39), B. decumbens accession CIAT 606 (42), BRUZ4X/4402 (44), FM9201/1873 (48), and SX99/0731 (52), respectively; lanes 8 to 17, seedlings generated from seeds of 10 artificially infected B. brizantha CIAT 26110 (15) plants; lanes 18 to 25 , seedlings generated from seeds of eight naturally infected $B$. brizantha CIAT 16320 (32) plants; lanes 26 and 27, seedlings generated from seeds of two endophyte-free B. brizantha CIAT 16320 (32-25) plants; lane M, 100-bp ladders. Numbers in parentheses after Brachiaria genotype codes or accession numbers are individual plant-tracking numbers. 
Mini Kits (QIAGEN, Valencia, CA) according to the manufacturer's instructions.

PCR amplifications. The specific primers P1 (5'-TTCGAATGATAAGGCAGATC- $3^{\prime}$ ) and P4 (5'-ACGCATCCACTGTATGCTAC-3') were used in the PCR reactions. Amplifications were carried out in a Programmable Thermal Controller (MJ Research, Inc., Waltham, MA) programmed to 44 cycles for genomic DNA of endophyte pure cultures or plant leaves, and 54 cycles for DNA from Brachiaria seeds. The latter set of cycles comprised a 30 -s denaturation step at $94^{\circ} \mathrm{C}(3 \mathrm{~min}$ for the first cycle) followed by $1 \mathrm{~min}$ at $65^{\circ} \mathrm{C}$ and primer extension for $1 \mathrm{~min}(10 \mathrm{~min}$ in the final cycle) at $72^{\circ} \mathrm{C}$. The amplification products were separated by electrophoresis in a $1.0 \%$ agarose gel (Bio-Rad Laboratories, Inc., Hercules, CA), stained with ethidium bromide, and photographed under UV lighting.

\section{RESULTS AND DISCUSSION}

Plant inoculation with $A$. implicatum. The plant inoculation procedure resulted in a high mortality rate $(74 \%)$, perhaps because of damage to the apical meristem. Among the plants that survived, only $7 \%$ tested positive for the presence of $A$. implicatum when examined 4 to 6 weeks after inoculation. However, the number of tillers was sufficient to conduct the studies, as we could propagate the plants vegetatively, and because the inoculated plants were apomictic.

Seed infection. Seeds were collected from plants whose tissue samples tested positively for A. implicatum (Fig. 1), as well as from other plants that were confirmed to be either endophyte infected or endophyte free. All DNA from seeds of endophyte-infected plants (both naturally infected and artificially inoculated ones) generated a 500-bp amplified product (Fig. 2). No amplification product was detected with DNA of seeds harvested from endophyte-free plants.

Serological assays and tissue-staining procedures have been used in endophytetemperate grass associations, including seeds $(1,2)$. The use of staining procedures, culturing on agar media, or a combination of procedures is not only timeconsuming, but also not $100 \%$ accurate in plant tissues where fungal hyphae are of limited quantity and/or sparsely distributed. The development of PCR primers that are highly specific to A. implicatum enabled us to rapidly and accurately screen Brachiaria genotypes for the presence or absence of the fungus.

Seed transmission. The primer pair $\mathrm{P} 1 / \mathrm{P} 4$, developed according to the sequence of a cloned random amplified polymorphic DNA (RAPD) fragment of $A$. implicatum, allowed the precise and rapid detection of A. implicatum in Brachiaria grasses and permitted a differentiation between endophytic and nonendophytic fungi associated with Brachiaria species (12). This PCR-based assay developed to detect endophytic A. implicatum in tissues of Brachiaria species is accurate, sensitive, and specific. The assay was used to determine transmission of the endophytic fungus to Brachiaria seeds and seedlings derived from them.

A single band of about 500 bp was amplified in all examined isolates of $A$. implicatum (12). Endophyte-infected and endophyte-free plants were also consistently differentiated by this primer combination (Fig. 1). Some of these results were further confirmed by traditional methods of culturing and tissue staining (data not shown).

Seedlings generated from seed samples of endophyte-infected and endophyte-free plants had consistently tested positive or negative, respectively, for the diagnostic 500-bp amplified product (Fig. 3). Instances of plant-to-seed-to-seedling transmission were found consistently in both naturally endophyte-infected and artificially inoculated plants, indicating that transmission through seeds is near $100 \%$ in apomictic Brachiaria. From these results, we conclude that $A$. implicatum maintains its symbiotic association with species of Brachiaria through seed transmission. This is the first report on A. implicatum transmission in seeds of Brachiaria species.

The practical implication of seed transmission of endophytes in Brachiaria is significant: once associated with the plant, the fungus can perpetuate itself through seed, especially in apomictic genotypes of Brachiaria, for as long as seed storage conditions do not diminish the survival of the fungus. Several Brachiaria hybrids obtained from CIAT's forage breeding program were shown to harbor A. implicatum (Figs. 1 to 3 ). We may be able to exploit this association and its high seed transmission by using a transgenic A. implicatum as a vehicle for production and delivery of gene products of agronomic interest into the host plant to enhance protective benefits and other traits, and thus improve livestock production.

\section{ACKNOWLEDGMENTS}

We thank Alvaro Baena, Ximena P. Bonilla, and Gustavo Segura for their technical support.

\section{LITERATURE CITED}

1. Bacon, C. W., and White, J. F. 1994. Stains, media, and procedures for analyzing endophytes. Pages 47-56 in: Biotechnology of Endophytic Fungi of Grasses. C. W. Bacon and J. F. White, eds. CRC Press, Boca Raton, FL.

2. Clark, E. M., White, J. F., and Patterson, R. M. 1983. Improved histochemical techniques for the detection of Acremonium coenophialum in tall fescue and methods of in vitro culture of the fungus. J. Microbiol. Methods 1:149-155.

3. Clay, K. 1989. Clavicipitaceous endophytes of grasses: Their potential as biocontrol agents. Mycol. Res. 92:1-12.
4. Clay, K. 1990. Fungal endophytes of grasses. Annu. Rev. Ecol. Syst. 21:275-297.

5. Doss, R. P., Clement, S. L., Kuy, S.-R., and Welty, R. E. 1998. A PCR-based technique for detection of Neotyphodium endophytes in diverse accessions of tall fescue. Plant Dis. 82:738-740.

6. Doss, R. P., and Welty, R. E. 1995. A polymerase chain reaction-based procedure for detection of Acremonium coenophialum in tall fescue. Phytopathology 85:913-917.

7. Funk, C. R., White, R. H., and Breen, J. P. 1993. Importance of Acremonium endophytes in turfgrass breeding and management. Agric. Ecosyst. Environ. 44:215-232.

8. Groppe, K., and Boller, T. 1997. PCR assay based on a microsatellite-containing locus for detection and quantification of Epichlöe endophytes in grass tissues. Appl. Environ. Microbiol. 63:1543-1550.

9. Gwinn, K. D., and Gavin, A. M. 1992. Relationship between endophyte infestation level of tall fescue seed lots and Rhizoctonia zeae seedling disease. Plant Dis. 76:911-914.

10. Henson, J. M., and French, R. 1993. The polymerase chain reaction and plant disease diagnosis. Annu. Rev. Phytopathol. 31:81109.

11. Kelemu, S., and Dongyi, H. 2003. Endophytic fungus Acremonium implicatum is seed transmitted in Brachiaria spp. (Abstr.) Phytopathology 93:S43.

12. Kelemu, S., Dongyi, H., Guixiu, H., and Takayama, Y. 2003. Detecting and differentiating Acremonium implicatum: Developing a PCRbased method for an endophytic fungus associated with the genus Brachiaria. Mol. Plant Pathol. 4:115-118.

13. Kelemu, S., and Takayama, Y. 1998. An endophytic fungus in the tropical forage grass Brachiaria brizantha: Effect on a leaf spot disease. (Abstr.) Phytopathology 88:S46.

14. Kelemu, S., White, J. F., Muñoz, F., and Takayama, Y. 2001. An endophyte of the tropical forage grass Brachiaria brizantha: Isolating, identifying, and characterizing the fungus, and determining its antimycotic properties. Can. J. Microbiol. 47:55-62.

15. Kimmons, C. A., Gwinn, K. D., and Bernard, E. C. 1990. Nematode reproduction on endophyte-infected and endophyte-free tall fescue. Plant Dis. 74:757-761.

16. Latch, G. C. M., and Christensen, M. J. 1985. Artificial infections of grasses with endophytes. Ann. Appl. Biol. 107:17-24.

17. Miles, J. W., and Valle, do C. B. 1991. Assessment of reproductive behaviour of interspecific Brachiaria hybrids. Apomixis Newsl. 3:9-10.

18. Murashige, T., and Skoog, F. 1962. A revised medium for rapid growth and bioassays with tobacco tissue culture. Physiol. Plant 15:473-479.

19. Petrini, O., Sieber, T. N., Toti, L., and Viret, O. 1992. Ecology, metabolite production, and substrate utilization in endophytic fungi. Natural Toxins 1:185-196.

20. Pryor, B. M., and Gilbertson, R. L. 2001. A PCR-based assay for detection of Alternaria radicina on carrot seed. Plant Dis. 85:18-23.

21. Rowan, D. D., and Latch, G. C. M. 1994. Utilization of endophyte-infected perennial rye grasses for increased insect resistance. Pages 169-183 in: Biotechnology of Endophytic Fungi of Grasses. C. W. Bacon and J. F. White, eds. CRC Press, Boca Raton, FL.

22. Schardl, C. L. 1996. Epichlöe species: Fungal symbionts of grasses. Annu. Rev. Phytopathol. 34:109-130.

23. Schardl, C. L., and Phillips, T. D. 1997. Protective grass endophytes: Where are they from and where are they going? Plant Dis. 81:430-438. 